\title{
A Comparative Evaluation of Dexamethasone and Tramadol as Adjuvant to Levobupivacaine in Supraclavicular Block
}

\author{
Rangit Priyakar Pandey ${ }^{1}$, Richa Chandra ${ }^{2}$ \\ ${ }^{1,2}$ Professor, Department of Anaesthesia, Rajshree Medical Research Institute, Bareilly, Uttar Pradesh, India.
}

\section{Abstract}

Background: The present study was conducted to evaluate and compare dexamethasone and tramadol as adjuvant to levobupivacaine in supraclavicular block. Subjects and Methods: The present study was conducted on 50 patients of American Society of Anesthesiologists (ASA) grade I and II. Patients were divided in to two groups of 25 each. In group I, $30 \mathrm{ml}$ of $0.5 \%$ levobupivacaine hydrochloride plus $2 \mathrm{ml}$ tramadol (100 mg) was used. In group II, $30 \mathrm{ml}$ of $0.5 \%$ levobupivacaine hydrochloride plus $2 \mathrm{ml}$ dexamethasone ( $8 \mathrm{mg}$ ) was used. Visual Analogue Scale was used. The onset of sensory and motor block was evaluated. Results: The mean onset of sensory block in group I was 5.41 minutes and in group II was 3.86 minutes, motor onset was 9.12 minutes in group I and 7.25 minutes in group II, duration of sensory block in group I was 12.14 hours and in group II was 15.34 hours, duration of motor block in group I was 14.34 hours and I group II was 16.23 hours, duration of analgesia in group I was 16.1 hour and in group II was 18.4 hours. The difference was significant difference $(\mathrm{P}<0.05)$. The mean VAS score in group II was better as compared to group I $(\mathrm{P}<0.05)$. Conclusion: Authors found that dexamethasone is a better adjuvant than tramadol when added to levobupivacaine in supraclavicular brachial plexus block.

Keywords: Levobupivacaine, Supraclavicular brachial plexus block, Tramadol.

Corresponding Author: Dr. Richa Chandra, Professor, Department of Anaesthesia, Rajshree Medical Research Institute, Bareilly, Uttar Pradesh, India.

Received: January 2020

Accepted: January 2020

\section{Introduction}

Brachial plexus block is a regional anesthesia technique that is sometimes employed as an alternative or as an adjunct to general anesthesia for surgery of the upper extremity. ${ }^{[1]}$ This technique involves the injection of local anesthetic agents in close proximity to the brachial plexus, temporarily blocking the sensation and ability to move the upper extremity.

There are several techniques for blocking the nerves of the brachial plexus. These techniques are classified by the level at which the needle or catheter is inserted for injecting the local anesthetic - interscalene block on the neck, supraclavicular block immediately above the clavicle, infraclavicular block below the clavicle and axillary block.

The brachial plexus is formed by distributions from C5 to T1. Blockade of the brachial plexus can provide surgical anesthesia of the hand, upper, lower arm and shoulder depending on the approach. ${ }^{[2]} \mathrm{A}$ thorough knowledge of anatomy and its impact on the two techniques is important for success. Supraclavicular block is one of the most effective anaesthetic procedures in an operation of upper extremity. The supraclavicular block is often called as spinal anaesthesia of upper extremities because of ubiquitous application for upper extremity surgeries. The reason for its high success rate is in its anatomic characteristics. ${ }^{[3]}$

Levobupivacaine which is less toxic is a best choice for local
Anesthesia, as it got less sodium channels affinity its cardiovascular system adverse effects are very less Levobupivacaine being more lipids soluble it got high potency than Ropivacaine. Levobupivacaine exerts its pharmacological action through reversible blockade of neuronal sodium channels. Myelinated nerves are blocked through exposure at the nodes of Ranvier more readily than unmyelinated nerves; and small nerves are blocked more easily than larger ones. ${ }^{[4]}$

Recently dexamethasone has been studied as a local anaesthetic adjuvant for peripheral nerve block. As a perineural adjuvant the safety profile of dexamethasone is promising. No trial reported neurotoxicity attributable to dexamethasone. Tramadol, a synthetic 4-phenyl-piperidine analog of codeine exerts its central analgesic activity through activation of mu-receptor. It also has peripheral local anesthetic properties that led to its use as an additive in peripheral nerve blocks. First, it stimulates the mu receptor and to lesser extent delta and kappa-opioids receptors ${ }^{[5]}$ The present study was conducted to evaluate and compare dexamethasone and tramadol as adjuvant to levobupivacaine in supraclavicular block.

\section{Subjects and Methods}

The present study was conducted in the department of 
0

Anaesthesia. It comprised of 50 patients of American Society of Anesthesiologists (ASA) grade I and II of age group 18 60 years of either sex scheduled to undergo surgery of the forearm or hand under supraclavicular brachial plexus block with levobupivacaine with addition of dexamethasone and dexmedetomidine as adjutants were included. A written consent was taken from all the participants. The study was undertaken after the approval of Institutional Ethics Committee.

Patients were divided in to two groups of 25 each. In group I, $30 \mathrm{ml}$ of $0.5 \%$ levobupivacaine hydrochloride plus $2 \mathrm{ml}$ tramadol $(100 \mathrm{mg})$ was used. In group II, $30 \mathrm{ml}$ of $0.5 \%$ levobupivacaine hydrochloride plus $2 \mathrm{ml}$ dexamethasone $(8$ $\mathrm{mg}$ ) was used.

Visual Analogue Scale was used. The end mark ' 0 ' means 'no pain' and end marked '10' means 'severe pain'. All patients received tablet Alprazolam $0.25 \mathrm{mg}$ orally one night prior to surgery with 8 hours of fasting. On the day of surgery, injection Glycopyrrolate $0.2 \mathrm{mg}$, Inj. Midazolam 2 $\mathrm{mg}$ were given 45 minutes before surgery. Patients were assessed for loss of sensation to pin prick over the C5 - T1 dermatomes using a three point's scale every 2 minutes for the first 20 minutes and every 5 minutes thereafter till 30 minutes. The onset of sensory and motor block was evaluated. The results were analyzed. $\mathrm{P}$ value of less than 0.05 was considered significant.

\section{Results}

\begin{tabular}{l}
\hline Table 1: Comparison of parameters \\
\begin{tabular}{|l|l|l|l|}
\hline Parameters & Group I & Group II & P value \\
\hline Sensory onset (mins) & $5.41 \pm 1.87$ & $3.86 \pm 0.77$ & 0.01 \\
\hline Motor onset (mins & $9.12 \pm 3.29$ & $7.25 \pm 2.91$ & 0.05 \\
\hline Duration of sensory block & $12.14 \pm$ & $15.34 \pm$ & 0.02 \\
(Hours) & 2.37 & 4.69 & \\
\hline Duration of motor block (Hours) & $14.34 \pm 2.18$ & $16.23 \pm 3.42$ & 0.05 \\
\hline Duration of analgesia (Hours) & $16.1 \pm 4.33$ & $18.4 \pm 5.25$ & 0.04 \\
\hline
\end{tabular}
\end{tabular}

Table 1, Graph 1 shows that mean onset of sensory block in group I was $5.41 \pm 1.87$ minutes and in group II was $3.86 \pm$ 0.77 minutes, motor onset was $9.12 \pm 3.29$ minutes in group I and $7.25 \pm 2.91$ minutes in group II, duration of sensory block in group I was $12.14 \pm 2.37$ hours and in group 2 was $15.34 \pm 4.69$ hours, duration of motor block in group I was $14.34 \pm 2.18$ hours and I group II was $16.23 \pm 3.42$ hours, duration of analgesia in group I was $16.1 \pm 4.33$ hour and in group II was $18.4 \pm 5.25$ hours. The difference was significant difference $(\mathrm{P}<0.05)$.

Table 2: Intraoperative and postoperative VAS scores in both groups

\begin{tabular}{|l|l|l|l|}
\hline Time (hours) & Group I & Group II & P value \\
\hline 1 & 0 & 0 & \\
\hline 2 & 0 & 0 & \\
\hline 4 & 0 & 0 & \\
\hline 6 & 0 & 0 & \\
\hline 8 & 0 & 0 & \\
\hline 10 & 0 & 0 & \\
\hline 12 & 0 & 0 & \\
\hline 18 & 2.46 & 1.54 & 0.05 \\
\hline 21 & 2.68 & 2.62 & 0.12 \\
\hline 24 & 2.32 & 2.16 & 0.05 \\
\hline
\end{tabular}

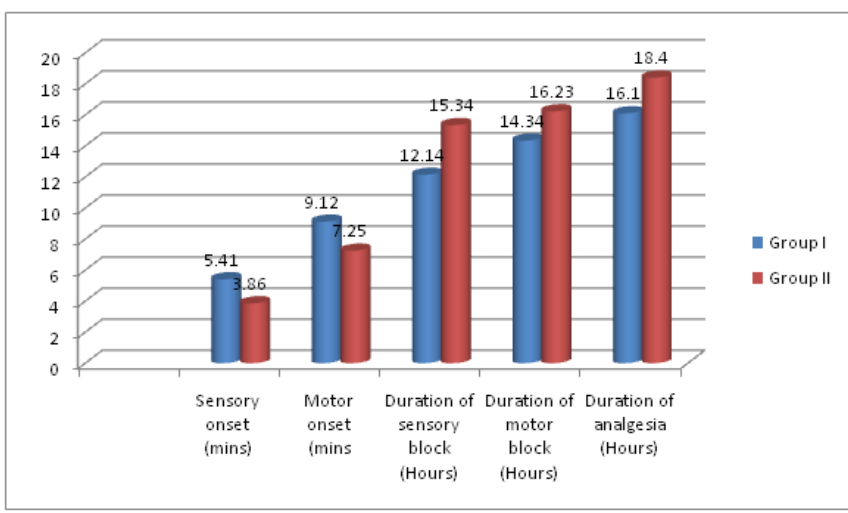

Graph 1: Comparison of parameters

Table 2, graph 2 shows the mean VAS score in group II was better as compared to group I ( $\mathrm{P}<0.05)$.

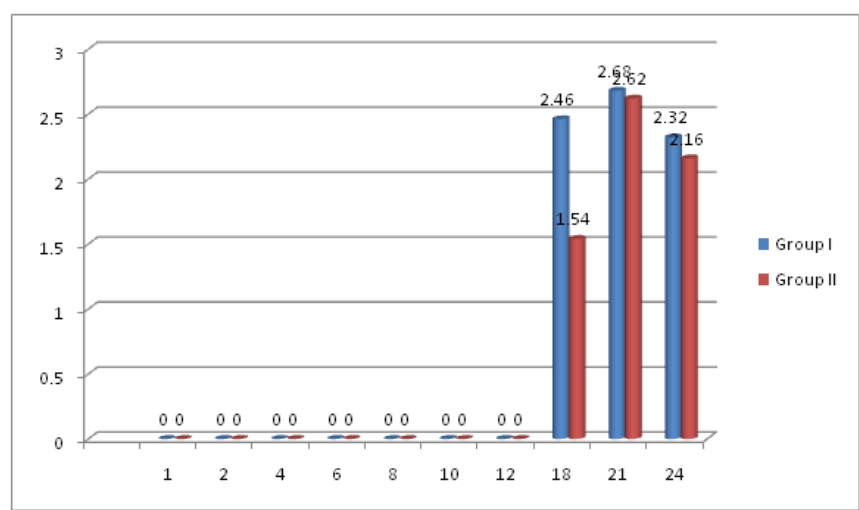

Graph 2: Intraoperative and postoperative VAS scores in both groups

\section{Discussion}

Anaesthetic agents are available in the form of gases, injections and jellies. The American board of anesthesiology lists "the aim of post operative pain relief is to prevent subjective discomfort in addition to early mobilization and shortened hospital stay and to enhance restoration of physiological function of operated region." ${ }^{[6]}$

The brachial plexus is primarily formed by ventral rami of C5-T1. C4 and T2 make minor contributions. Contributions from C5-T1 come together, then separate to form trunks, divisions, cords, and main branches. At the level of the anterior and middle scalene muscles the trunks are already formed. Upper, middle, and lower trunks course over the lateral border of the first rib and under the clavicle. At this point, each trunk will separate into anterior and posterior divisions. As the brachial plexus emerges under the clavicle, the anterior and posterior divisions come together to form three cords ${ }^{[7]}$ The present study was conducted to evaluate and compare dexamethasone and tramadol as adjuvant to levobupivacaine in supraclavicular block.

In present study, patients were divided in to two groups of 25 each. In group I, $30 \mathrm{ml}$ of $0.5 \%$ levobupivacaine hydrochloride plus $2 \mathrm{ml}$ tramadol $(100 \mathrm{mg})$ was used. In group II, $30 \mathrm{ml}$ of $0.5 \%$ levobupivacaine hydrochloride plus $2 \mathrm{ml}$ dexamethasone $(8 \mathrm{mg})$ was used. Pathak et $\mathrm{al}^{[8]}$ 
0

included 60 patients of either sex, age between 18-70 years belonging to ASA Grade I and II undergoing elective or emergency surgeries of upper limb under supraclavicular brachial plexus block. Patients were randomly divided in group A (40 ml volume of lignocaine $2 \%$ with adrenaline $(1: 200000)+0.5 \%$ bupivacaine $)$ and group B (40 ml volume of lignocaine $2 \%$ with adrenaline $(1: 200000)+0.5 \%$ bupivacaine with dexamethasone $8 \mathrm{mg}$ ). Group B had early onset and prolonged duration of sensory and motor block as well as prolonged duration of analgesia as compared to group A. None of the patients had bradycardia, hypotension or any other side effects.

We observed that mean onset of sensory block in group I was 5.41 minutes and in group II was 3.86 minutes, motor onset was 9.12 minutes in group I and 7.25 minutes in group II, duration of sensory block in group I was 12.14 hours and in group II was 15.34 hours, duration of motor block in group I was 14.34 hours and I group II was 16.23 hours, duration of analgesia in group I was 16.1 hour and in group II was 18.4 hours. The difference was significant difference $(\mathrm{P}<0.05)$.Shrestha et $\mathrm{al}^{[9]}$ who found that the onset of sensory and motor block was significantly earlier in dexamethasone group (10.36 \pm 1.99 and $12 \pm 1.64$ minutes $)$ compared to control group $(12.9 \pm 2.23$ and $18.03 \pm 2.41)$ minutes.

We found that the mean VAS score in group II was better as compared to group I $(\mathrm{P}<0.05)$. Arish et $\mathrm{al}^{[10]}$ enrolled 50 patients who received bupivacaine and bupivacaine with dexamethasone in supraclavicular brachial plexus block. The onset of analgesia, the onset of motor blockade and hemodynamic parameters oxygen saturation, heart rate, systolic and diastolic blood pressures were recorded during and $1 \mathrm{~h}$ after the procedure. There was no statistically significant difference in the onset of sensory and motor blockade between both the groups. The mean duration of sensory blockade in study group was $1075.20 \pm 144.831 \mathrm{~min}$ and in control group was found to be $288.00 \pm 103.923 \mathrm{~min}$ and the mean duration of motor blockade in study group was $475.20 \pm 114.787 \mathrm{~min}$ and in control group was found to be $218.40 \pm 64.52 \mathrm{~min}$ and was statistically significant $(\mathrm{P} \leq$
$0.001)$.

\section{Conclusion}

Authors found that dexamethasone is a better adjuvant than tramadol when added to levobupivacaine in supraclavicular brachial plexus block.

\section{References}

1. Clerc S, Vuilleumier H, Frascarolo P, Spahn DR, Gardaz JP. Is the effect of inguinal field block with $0.5 \%$ bupivacaine on postoperative pain after hernia repair enhanced by addition of ketorolac or $\mathrm{S}(+)$ ketamine? Clin J Pain 2005;21:101-5.

2. Noyan A. On effects of ketamine to axillary block in hand surgery. $\mathbf{J}$ Reconstr Microsurg 2002;18:197.

3. Jarbo K, Batra YK, Panda NB. Brachial plexus block with midazolam and bupivacaine improves analgesia. Can J Anaesth 2005;52:822-6.

4. Colombo G, Padera R, Langer R, Kohane DS. Prolonged duration local anesthesia with lipid-protein-sugar particles containing bupivacaine and dexamethasone. J Biomed Mater Res A 2005; 75:458-64.

5. Drager C, Benziger D, Gao F, Berde CB. Prolonged intercostal nerve blockade in sheep using controlled-release of bupivacaine and dexamethasone from polymer microspheres. Anesthesiology 1998;89:969 79.

6. Movafegh A, Razazian M, Hajimaohamadi F, Meysamie A. Dexamethasone added to lidocaine prolongs axillary brachial plexus blockade. Anesth Analg 2006;102:263-7.

7. Choi S, Rodseth R, McCartney CJ. Effects of dexamethasone as a local anaesthetic adjuvant for brachial plexus block: A systematic review and meta-analysis of randomized trials. $\mathrm{Br} \mathrm{J}$ Anaesth 2014;112:1-13.

8. Pathak RG, Anand PS, Rajendra NK. Supraclavicular brachial plexus block with and without dexamethasone - A comparative study. Int J Sci Res Publ 2012;12:1-7.

9. Patil BO, Sonavdekar SR, Mathur R. A Study on Effects of Dexmedetomidine Used as an Adjuvant in Epidural Post-Operative Analgesia. Asian J. Med. Res. 2019;8(3):AN01-AN04.

10. Arish BT, Babu DD, Lazarus SP, Chandar DD, Balasubramanian S, Kumar KS. Effect of Dexamethasone as an Adjuvant to Local Anesthetic in Supraclavicular Brachial Plexus Block. Int J Sci Stud 2016;3(10):147-153.

Copyright: ( $)$ the author(s), 2020. It is an open-access article distributed under the terms of the Creative Commons Attribution License (CC BY 4.0), which permits authors to retain ownership of the copyright for their content, and allow anyone to download, reuse, reprint, modify, distribute and/or copy the content as long as the original authors and source are cited.

How to cite this article: Pandey RP, Chandra R. A Comparative Evaluation of Dexamethasone and Tramadol as Adjuvant to Levobupivacaine in Supraclavicular Block. Acad. Anesthesiol. Int. 2020;5(1):100-102.

DOI: dx.doi.org/10.21276/aan.2020.5.1.20

Source of Support: Nil, Conflict of Interest: None declared. 